\title{
Cladosporium cladosporioides isolado de gato com carcinoma de células escamosas
}

\author{
[Cladosporium cladosporioides isolated from a cat with squamous cell carcinoma] \\ S.A. Jarrah ${ }^{1}$, C.C. Zanetti ${ }^{1}$, F.H. Maruyama ${ }^{2}$, A.T.H. Ito ${ }^{1}$, J.M.A. Rosa ${ }^{1}$, E.M. Colodel ${ }^{3}$, S.R. Lima $^{2}$, \\ L. Nakazato ${ }^{3}$, V. Dutra ${ }^{3 *}$ \\ ${ }^{1}$ Residência Uniprofissional - Hospital Veterinário - Universidade Federal de \\ Mato Grosso - Hovet - UFMT - Boa Esperança, Cuiabá, MT \\ ${ }^{2}$ Programa de pós-graduação - PPGVET/UFMT, Cuiabá, MT \\ ${ }^{3}$ Climev/Hovet - UFMT, Cuiabá, MT
}

\begin{abstract}
RESUMO
Este relato descreve o caso do Cladosporium cladosporioides isolado de uma lesão periocular de um felino atendido no Hospital Veterinário da Universidade Federal de Mato Grosso, em Cuiabá. A principal queixa do proprietário era uma lesão periocular, com piora no decorrer do tempo, havia aproximadamente quatro meses. Foi descrita a tentativa de tratamento da lesão com anti-inflamatórios e antibióticos, sem sucesso. $\mathrm{Na}$ anamnese foi relatado que o animal tinha acesso à rua e a hábitos de caça e que não havia outros animais da casa com lesão semelhante. $\mathrm{O}$ animal foi submetido à biópsia e citologia para um diagnóstico mais preciso do caso. Um fragmento foi encaminhado para o Laboratório de Patologia Veterinária e outro para o de Microbiologia Veterinária. Nas análises histopatológicas, houve compatibilidade com carcinoma de células escamosas e, nas lâminas de citologia, foi evidenciado um processo inflamatório agudo. Nas características macroscópicas e microscópicas da colônia, houve compatibilidade com Cladosporium sp. Posteriormente, o DNA foi extraído e sequenciado, confirmando a espécie Cladosporium cladosporioides. O objetivo deste relato foi descrever o isolamento dessa espécie em um felino com carcinoma de células escamosas.
\end{abstract}

Palavras-chave: felino, Cladosporium cladosporioides, lesão periocular

\begin{abstract}
This report describes a case of Cladosporium cladosporioides isolated from a cat with a periocular lesion at the Veterinary Hospital, Cuiaba-Brazil. Owner described his animal as having a periocular lesion treated unsuccessfully with anti-inflamatories and antibiotics. During anamnesis, it was reported that the animal has access to the street, hunting habits and none of the other animals of the house had a similar injury. The animal underwent biopsy and cytology for more accurate diagnosis of the case. A fragment was referred to the Veterinary Pathology Laboratory and another for Veterinary Microbiology. In the histopathological analysis of biopsy, it was compatible with squamous cell carcinoma and the cytology slides showed an acute inflammatory process. Microbiogical analysis isolated fungus with Cladosporium sp. Subsequently, DNA was extracted and sequenced confirming Cladosporium cladosporioides species. This paper reports the isolation of this species in a feline with squamous cell carcinoma.
\end{abstract}

Keyword: cat, Cladosporium cladosporioides, periocular lesion

\section{INTRODUÇÃO}

A feo-hifomicose caracteriza-se por uma infecção oportunista micótica cutânea, subcutânea ou sistêmica, causada por fungos

Recebido em 14 de setembro de 2016

Aceito em 3 de setembro de 2016

*Autor para correspondência (corresponding author)

E-mail: valdutra@cpd.ufmt.br dematiáceos, filamentosos, os quais apresentam melanina em sua parede e são comuns em climas quentes e úmidos (Alviano et al., 1991; Uchôa et al., 2012; Ma et al., 2013; Zhou et al., 2016). Alguns gêneros de fungos têm sido relatados mundialmente, gerando feo-hifomicose como 


\begin{abstract}
Exophiala, Phialophora, Cladosporium, Xylohypha, Curvularia, Dactylaria, Exserohilum, Bipolaris, Lecythophora e Alternaria (Sandoval-Denis, 2015).
\end{abstract}

O gênero Cladosporium é composto por diversas espécies, incluindo saprófitos e patógenos humanos, animais e vegetais. Desde que foi descoberto, em 1815, mais de 500 espécies foram descritas (Okada et al., 1996). Entre as espécies de Cladosporium, a Cladosporium cladosporioides tem sido relatada como um patógeno incomum distribuído mundialmente (Zhou et al., 2016).

Este relato descreve o isolamento de Cladosporium cladosporioides em felino com carcinoma de células escamosas.

\section{RELATO DO CASO}

Felino, macho, sem raça definida, 3,9kg, de aproximadamente oito anos, foi atendido no Hospital Veterinário da Universidade Federal de Mato Grosso, Cuiabá, sob a queixa principal de uma lesão periocular observada havia aproximadamente quatro meses, possivelmente associada a arranhaduras durante brigas. Durante a anamnese, foi relatado que o animal eventualmente tinha prurido no local.

O felino recebeu tratamento com colírios e pomadas. Foi administrada amoxicilina, mas o tratamento não foi completo devido ao fato de o animal ter o hábito de fugir e de caçar, bem como acesso à rua. Nenhum dos outros animais da casa apresentou lesão semelhante. Quanto a cuidados preventivos, o animal foi vacinado apenas contra a raiva, e a vermifugação estava desatualizada.

No exame físico, foram observados desidratação leve, linfonodos submandibulares aumentados, presença de estomatite, gengivite e lesão ulcerativa, de aproximadamente $3 \mathrm{~cm}$, no canto medial do olho esquerdo, com presença de secreção ocular amarelada em excesso. Inicialmente, as suspeitas eram de criptococose, esporotricose e carcinoma.

Para a realização da biópsia e da citologia (imprinting), o animal foi sedado com as medicações pré-anestésicas midazolam e tramadol, sendo posteriormente administrado propofol para indução anestésica. Um fragmento do tecido foi encaminhado para os Laboratórios de Microbiologia Veterinária e de Patologia Veterinária.

No exame citológico, as lâminas do imprinting estavam compostas predominantemente por infiltrado inflamatório constituído de neutrófilos, neutrófilos degenerados e macrófagos ocasionais, confirmando apenas a presença de um processo inflamatório agudo. No exame histopatológico, as lâminas foram coradas com hematoxilina-eosina (HE) e prata pela técnica de Grocott. O diagnóstico morfológico da biópsia de acordo com a coloração de HE foi compatível com carcinoma de células escamosas. A coloração de prata não evidenciou nenhuma estrutura fúngica. Para o exame microbiológico, o tecido foi semeado em ágar Sabouraud e ágar Sabouraud acrescido de cloranfenicol nas temperaturas de $25^{\circ}$ e $30^{\circ} \mathrm{C}$.

No resultado do exame microbiológico, observou-se colônia de aspecto aveludado e cor olivácea nos cultivos em ambas as temperaturas no ágar Sabouraud acrescido e não de cloranfenicol. No exame direto, observaram-se hifas septadas, conídios sem septos ou apenas um septo em formato cilíndrico sugerindo Cladosporium cladosporioides, de acordo com o Atlas of Clinical Fungi (Hoog et al., 2000). O DNA do isolado foi extraído de acordo com o protocolo de Del Poeta et al. (1999) e realizou-se a técnica de reação em cadeia de polimerase (PCR) com os oligonucleotídeos da região Internal Transcript Spacer (ITS) 1 (5' $^{\prime}$ - TCC GTA GGT GAA CCT GCG G - 3') e ITS 4 ( $5^{\prime}$ TCC TCC TAT TGA TAT GC - 3'). Para a PCR, foi utilizada uma reação de volume final de $25 \mu \mathrm{L}$ (20pmol de cada oligonucleotídeo, $3 \mathrm{mM}$ de $\mathrm{MgCl}, 1 \mathrm{x}$ tampão $10 \mathrm{x}$ (200mM Tris- $\mathrm{HCl} \mathrm{pH}$ : 8,4; 500mM KCl), 0,2U de Taq DNA polimerase e 10ng de DNA.

A reação foi realizada em termociclador (BIORAD MyCycler Thermal Cycler) com desnaturação inicial a $95^{\circ} \mathrm{C}$ por 10 minutos, seguida de 40 ciclos de 15 segundos de desnaturação a $95^{\circ} \mathrm{C}$, anelamento a $57^{\circ} \mathrm{C}$ por 30 segundos e extensão por um minuto a $72^{\circ} \mathrm{C}$; com um ciclo de extensão final de 10 minutos a $72^{\circ} \mathrm{C}$. Para o controle negativo, foi utilizada água ultrapura e para o controle positivo foram 
utilizados 10ng de DNA genômico de Aspergillus sp.

O produto de amplificação de aproximadamente $600 \mathrm{pb}$ foi analisado em eletroforese em gel agarose 1,0\% corado com Gel Red Red ${ }^{\mathrm{TM}}$ (Biotium ${ }^{\circledR}$ ), a $10 \mathrm{~V}$ por $\mathrm{cm}$, e observado em ChemiDoc $^{\mathrm{TM}}$ XRS utilizando-se o software ImageLab. $\mathrm{O}$ amplicon obtido foi purificado em GFX PCR DNA e Gel Band e sequenciado em ABI 3500 Genetic Analyzer (Applied Biosystems $\left.{ }^{\circledR}\right)$.

A sequência foi analisada pelo programa $B L A S T$ NCBI, obtendo-se $100 \%$ de identidade com a sequência do Cladosporium cladosporioides (número do acesso Gen Bank FJ490621).

O animal não retornou para avaliação, o tratamento para carcinoma e infecção fúngica não foi realizado e, após alguns meses, o animal faleceu por envenenamento.

\section{DISCUSSÃO}

O proprietário relatou um prurido eventual no gato, o qual pode ter potencializado a entrada do fungo no tecido subcutâneo. Sang et al. (2011) também relataram infecções cutâneas e subcutâneas causadas pelo Cladosporium cladosporioides.

Devido ao fato de a feo-hifomicose tornar-se cada vez mais frequente em felinos, esta deve ser investigada em casos de lesões com aspecto tumoral ou ulcerativo que não respondem à terapia antibacteriana (Ferreiro et al., 2007). Logo, a avaliação microbiológica neste caso foi fundamental para o diagnóstico desse animal.

Caso semelhante ocorreu com um urso pandagigante (Ailuropoda melanoleuca) adulto, que apresentou a lesão de feo-hifomicose na região nasal, causada por Cladosporium cladosporioides. Inicialmente notou-se perda de pelos, vermelhidão, inchaço da pele e área pruriginosa (Ma et al., 2013).

O exame histopatológico não evidenciou estruturas fúngicas, o que sugere que elas podem não ter sido coradas pela prata pela limitação física da técnica, pois o fragmento era muito pequeno.
No exame citológico da lesão do felino, foi confirmada apenas a presença de um processo inflamatório agudo. Situação semelhante, porém de constituição crônica, foi encontrada em um paciente humano chinês na avaliação da biópsia. $\mathrm{O}$ referido paciente desenvolveu feo-hifomicose disseminada pelo rosto, causada por Phialophora verrucosa, sendo encontrada na biópsia de pele uma intensa inflamação granulomatosa composta de infiltrado de neutrófilos, células gigantes de Langerhans e histiócitos epitelioides (Paixão et al., 2001).

Uma provável contaminação no exame microbiológico do tecido pode ser descartada, uma vez que o punch de pele foi devidamente embebido em álcool e flambado antes da semeadura. Além disso, há evidências de que o fungo provavelmente invadiu o tecido subcutâneo devido aos traumas observados no animal.

O felino não retornou para realização do tratamento e, meses após a consulta e o diagnóstico, veio a óbito por envenenamento. Lesões ulcerativas, nodulosas que não respondem à antibioticoterapia devem ser investigadas para presença fúngica, devido à expansão desses fungos saprófitos, os quais cada vez mais têm sido relatados como patógenos. A avaliação microbiológica nesses casos tem sido fundamental para o tratamento dos animais.

\section{REFERÊNCIAS}

ALVIANO, C.S.; FARBIARZ, S.R.; SOUZA, W. et al. Characterization of Fonsecaea pedrosoi Melanin. J. Gen. Microbiol., v.137, p.837-844, 1991.

DEL POETA, M.; TOFFALETTI, D.L; RUDE, T.H. et al. Topoisomerase $\mathrm{I}$ is essential in Criptococcus neoformans: role in pathobiology as an antifungal target. Genet. Soc. Am., v.152, p.167-178, 1999.

FERREIRO, L.; SPANAMBERG, A.; BORBA, M.R. et al. Feohifomicoses: infecções micóticas emergentes Acta Sci. Vet., v.35, p.239-241, 2007.

HOOG, G.S; GUARRO, J.; GENÉ, J.; FIGUEIRAS, M.J. Atlas of clinical fungi. Utrecht: Centraalbureau voor Schimmelcultures, 2000. 1126p. 
MA, X.; GU, Y.; LIU, X. et al. Phaeohyphomycotic dermatitis in a giant panda (Ailuropoda melanoleuca) caused by Cladosporium cladosporioides. Med. Mycol. Case Rep., v.2, p.119-121, 2013.

OKADA, K.; TAKIZAWA, K.; MAEBAYASHI, Y. et al. Ubiquinone systems of the genus Cladosporium and morphologically similar taxa. Immunol. Med. Microbiol., v.16, p.39-43, 1996.

PAIXAO, G.C.; SIDRIM, J.J.C.; CAMPOS, G.M.M. et al. Dermatófitos e fungos sapróbios isolados de cães e gatos na cidade de Fortaleza. Arq. Bras. Med. Vet. Zootec., v.2001, 2001. Disponível em:

http://www.scielo.br/scielo.php?script=sci_arttex t\&pid=S0102-09352001000500010>. Acessado em: 13/02/2016
SANDOVAL-DENIS, M.; SUTTON, D.A.; MARTIN-VINCENTE, A. et al. Cladosporium species recovered from clinical samples in the United States. J. Clin. Microbiol., v.53, p.29903000, 2015.

SANG, H.; ZHENG, X.E.; ZHOU, W.Q. et al. A case of subcutaneous phaeohyphomycosis caused by Cladosporium cladosporioides and its treatment. Mycoses, v.55, p.195-197, 2011.

UCHÔA, I.C.P.; SANTOS, J.R.S.; SOUZA, A.M.; DANTAS, A.F.M.; BORGES, O.M.M.; MEDEIROS, L.C. Feo-hifomicose sistêmica em cão. Ciência Rural. v.42, p.670-674, 2012.

ZHOU, Y.B.; CHEN, P.; SUN, T.T. et al. Acnelike subcutaneous phaeohyphomycosis caused by Cladosporium cladosporioides: a rare case report and review of published literatures. Mycopathologia, v.181, p.567-573, 2016. 